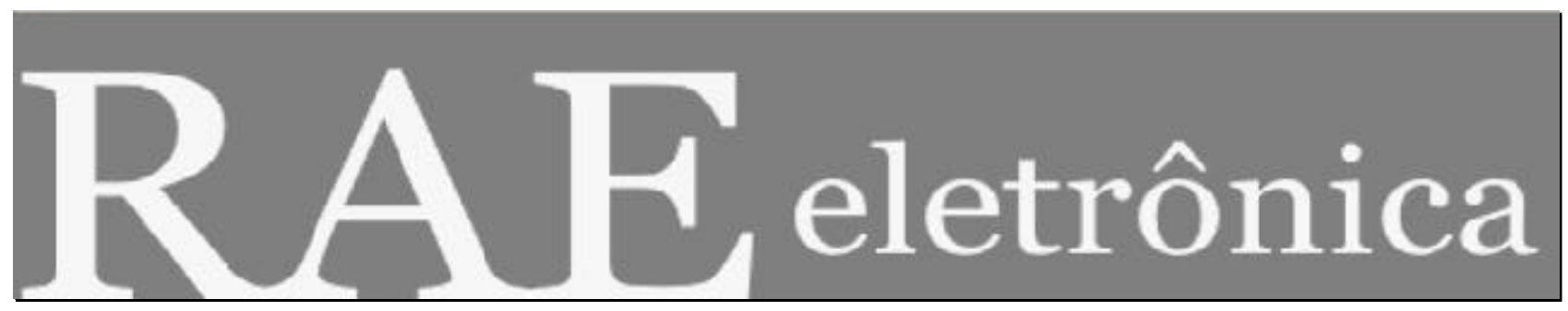

RAE-DOCUMENTO

RAE-DOCUMENTO

RAE-DOCUMENT

UMA PERSPECTIVA ITALIANA DO EMPREENDEDORISMO: ENTREVISTA COM ALBERTO MARTINELLI

UNA PERSPECTIVA ITALIANA DEL EMPREENDEDORISMO: ENTREVISTA CON ALBERTO MARTINELLI

AN ITALIAN VIEW OF ENTREPRENEURSHIP: INTERVIEW WITH ALBERTO MARTINELLI

Por:

MAURÍCIO C. SERAFIM, FGV-EAESP

ISABELA LEAO, UNIVERSITÀ DEGLI STUDI DI MILANO

RAE-eletrônica, v. 6, n. 2, Art. 17, jul./dez. 2007

http://www.rae.com.br/eletronica/index.cfm?FuseAction=Artigo\&ID=5057\&Secao=RAE-

DOCUMENTO $\&$ Volume $=6 \&$ Numero $=2 \& A n o=2007$

CCopyright, 2007, RAE-eletrônica. Todos os direitos, inclusive de tradução, são reservados. É permitido citar parte de artigos sem autorização prévia desde que seja identificada a fonte. A reprodução total de artigos é proibida. Os artigos só devem ser usados para uso pessoal e nãocomercial. Em caso de dúvidas, consulte a redação: raeredacao@fgvsp.br.

A RAE-eletrônica é a revista on-line da FGV-EAESP, totalmente aberta e criada com o objetivo de agilizar a veiculação de trabalhos inéditos. Lançada em janeiro de 2002, com perfil acadêmico, é dedicada a professores, pesquisadores e estudantes. Para mais informações consulte o site www.rae.com.br/eletronica.

RAE-eletrônica

ISSN 1676-5648

(C2007 Fundação Getulio Vargas - Escola de Administração

de Empresas de São Paulo. 


\title{
UMA PERSPECTIVA ITALIANA DO EMPREENDEDORISMO: ENTREVISTA COM ALBERTO MARTINELLI
}

\author{
Maurício C. Serafim \\ Doutorando em Administração de Empresas na FGV-EAESP \\ E-mail: serafim.gv@gmail.com
}

\begin{abstract}
Isabela Leao
Doutoranda em Estudos Políticos e Relações Internacionais na Università degli Studi di Milano E-mail: isnleao@gmail.com
\end{abstract}

\begin{abstract}
Alberto Martinelli é professor de Sociologia Econômica e Ciência Política na Università degli Studi di Milano (Universidade de Milão). Também leciona Sociologia na Università Bocconi e trabalhou em outras universidades, como as de Berkeley, Stanford e New York. Suas áreas de pesquisa incluem empreendedorismo, relações internacionais e políticas sociais. Martinelli é autor de vários artigos e livros, dentre os quais Global Modernization (Sage, 2005), Il Bilancio Sociale (com A. Chiesi e M. Pellegatta, Il Sole/24 ore, 2000), Recent Social Trends in Italy (com A. Chiesi e S. Stefanizzi, McGillQueen's University Press, 1999), International Markets and Global Firms (Sage, 1991) e Economy and Society (organizado com N. J. Smelser, Sage, 1990).

Martinelli veio ao Brasil para proferir a palestra de abertura do XXXI Encontro da ANPAD no Rio de Janeiro. A entrevista que se segue, realizada ainda na Itália, aborda o campo do Empreendedorismo e sua relação com a Sociologia Econômica, imigração, e se estende a questões de global governance e relações internacionais, temas com os quais vem trabalhando na Universidade de Milão.
\end{abstract}

\footnotetext{
Percebe-se uma retomada no campo acadêmico de estudos sobre Empreendedorismo. Qual o principal motivo dessa retomada?

O Empreendedorismo é tipicamente um tema de pesquisa baseado em várias disciplinas e desenvolvido por estudiosos que têm oferecido contribuições interdisciplinares, como Weber (um sociólogo com uma profunda cultura econômica) e Schumpeter (um economista com forte intuição sociológica). O 


\section{RAEDOCUMENTO - UMA PERSPECTIVA ITALIANA DO EMPREENDEDORISMO: ENTREVISTA COM ALBERTO MARTINELLI \\ Maurício C. Serafim - Isabela Leao}

interesse renovado pelo Empreendedorismo e o retorno aos estudos desse tema nos direcionam a uma pluralidade de fatores: ao crescimento da colaboração interdisciplinar entre economistas, sociólogos, antropólogos e cientistas políticos; à atenuação da força da ideologia marxista - que não faz a distinção entre capitalistas e empreendedores - e que tende a incluir ambos a um julgamento fortemente crítico; ao reconhecimento do papel fundamental que as pequenas empresas familiares e o empreendedorismo social possuem no desenvolvimento econômico de um país, como têm mostrado a teoria e ação de personagens como Muhammad Yunus (o "banqueiro dos pobres" e ganhador do prêmio Nobel da Paz de 2006) e Hernando De Soto (economista peruano); à crescente importância do empreendedorismo entre as mulheres e os imigrantes como canais de emancipação e integração social; e, por fim, à crescente atenção para o papel exercido pelas empresas transnacionais como atores globais, no mais amplo contexto das análises dos complexos processos da globalização.

Como você entende o estado atual do campo acadêmico do Empreendedorismo? É possível se falar de criação de teorias?

O atual campo de estudos é caracterizado por um certo desequilíbrio entre uma abundância de estudos de casos de atividades empreendedoras, de um lado, e por uma escassez de modelos interpretativos, de outro. A análise do empreendedorismo continua a ser fortemente embasada em construções teóricas dos clássicos - Schumpeter em particular - e em algumas abordagens mais recentes da teoria das organizações. Entretanto, há a exigência de atualizá-la e desenvolvê-la utilizando de uma melhor maneira os conceitos da teoria sociológica e das ciências sociais em geral, tais como - apenas para citar alguns - imersão (embededdness), capital social, confiança, stakeholder e desenvolvimento sustentável.

\section{E por que estudar o Empreendedorismo? Quais são os fenômenos atuais no campo da} Administração que devem ser abordados?

Um dos motivos para se estudar o Empreendedorismo é por constituir, por muitos aspectos, o fatorchave do desenvolvimento econômico. Entre os atuais fenômenos no campo da Administração que poderiam ser mais aprofundados posso citar, primeiramente, a complexa rede de relações entre o empreendedor e os stakeholders da empresa à luz de uma teoria multi-stakeholder da firma. Um segundo fenômeno que pode ser citado é a relação entre a propriedade e o controle, ou melhor, entre a estratégia e os comportamentos dos empreendedores, dos gerentes e dos acionistas e investidores (também à luz da globalização dos mercados financeiros e de seus efeitos, como o dos stock options dos dirigentes). Outros fenômenos são a relação entre estratégia e estrutura organizacional, a estratégia 
de marketing e as relações com os consumidores no mercado global, o estudo da cadeia de valor, a relação entre o crescimento econômico e a preservação ambiental, que é assumida no conceito de desenvolvimento sustentável.

Qual a situação atual do debate acerca do Empreendedorismo e Administração na Itália? Quais são os autores italianos mais importantes?

$\mathrm{Na}$ Iália há interessantes pesquisadores e estudiosos de organizações empresariais como Bonazzi, Butera, Gherardi e Grandori, e de relações industriais, como Ferrarotti, Baglioni, Cella e Regini. Os estudiosos de Empreendedorismo são menos numerosos, mas têm produzido análises bastante interessantes. Posso citar os pesquisadores Pagani, Gallino e Chiesi. Sobre a situação do debate atual de Empreendedorismo na Itália, estamos avançando bem. Juntamente com Antonio Chiesi e um orientando meu, Dalla Chiesa, realizei a pesquisa empírica mais completa sobre os empreendedores italianos publicada até então, com o título I grandi imprenditori italiani (Milano: Feltrinelli, 1981). Com Chiesi, Maraffi e Lanzalaco, publiquei uma análise da representação política dos empreendedores italianos, com o título L'azione collettiva degli imprenditori italiani (Milano: Comunità, 1999).

\section{Como o estudo do Empreendedorismo pode ser adaptado a países em desenvolvimento como o}

\section{Brasil? Que contribuições este campo pode oferecer?}

O Brasil é um dos países mais importantes em desenvolvimento, com grandes possibilidades de se tornar uma das grandes potências econômicas do futuro próximo. O empreendedorismo, nas suas diversas formas de empresa familiar, sociedade por ações, empresa pública, empresa social e cooperativa, é um fator fundamental de crescimento econômico e pode ser também fator fundamental de desenvolvimento social, caso se instaure uma relação apropriada entre o mercado e o Estado, livre iniciativa empresarial e Estado de Direito, e caso se desenvolva um empreendedorismo socialmente responsável que exercite o poder de decisão, não esquecendo os próprios deveres legais e legítimos em relação a uma pluralidade de stakeholders (funcionários, acionistas, consumidores, fornecedores, instituições estatais e comunidade local).

Você também é um estudioso do fenômeno da imigração. Quais são as relações possíveis de se estabelecer entre o Empreendedorismo e a imigração?

Examinei esta relação em alguns artigos em que abordei o empreendedorismo étnico, nos quais defendo que empreendedores imigrantes que obtiveram êxito são aqueles que sabem se mover com 
destreza em um duplo contexto, quais sejam, o contexto político-institucional do capitalismo de mercado e suas experiências socioculturais adquiridas (double embeddedness). $\mathrm{O}$ desenvolvimento do empreendedorismo entre os imigrantes é muito útil no governo dos fluxos migratórios porque contribui seja na integração dos imigrantes nos casos em que decidem permanecer definitivamente no país para o qual migrou, seja na reintegração dos imigrantes no país de origem dotados com novas competências técnicas, gerenciais, capital econômico e social (diáspora étnica), nos casos em que decidem retornar ao país de origem.

\section{É possível se afirmar que há diferenças entre grupos étnicos em relação à capacidade de desenvolvimento do empreendedorismo?}

A Sociologia, a partir da célebre tese de Weber sobre a ética protestante e o espírito do capitalismo, tem mostrado que existem diferenças nas atitudes e comportamentos das diversas religiões em relação à atividade econômica. Pesquisas mais recentes têm mostrado as diferenças entre as atitudes e comportamentos dos vários grupos étnicos. Todavia, não se trata de diferenças absolutamente impeditivas. Em cada grupo étnico, como em cada sociedade, existem indivíduos que têm propensão para a inovação empresarial, cujo êxito depende de uma multiplicidade de fatores contextuais.

\section{Em seu livro Global Modernization: Rethinking the Project of Modernity [London; Thousand} Oaks: Sage, 2005], você tratou sobre em que medida os Estados são capazes de aumentar seus recursos de modo a implementar políticas, redistribuição e bem-estar social. Como isso é possível para países em desenvolvimento?

Os países em desenvolvimento dispõem geralmente de uma grande "janela de oportunidade" demográfica, que corresponde à fase na qual o percentual de população ativa em relação ao total é muito elevado, porque, de um lado, diminuem os nascimentos e se encolhe a diferença de idade das crianças e dos adole scentes e, de outro, são ainda relativamente poucos os mais velhos que já não trabalham. Nessa fase, os governos têm à disposição recursos fiscais para destinar à modernização do país e à redução das desigualdades sociais, mas devem implementar uma política físcal que não diminua os investimentos privados.

No mundo atual parcialmente globalizado, os países em desenvolvimento atraem fluxos crescentes de investimentos externos diretos que podem iniciar e manter processos de desenvolvimento e modernização, com a condição que venham adequadamente orientados por uma hábil política 


\section{RAEDOCUMENTO - UMA PERSPECTIVA ITALIANA DO EMPREENDEDORISMO: ENTREVISTA COM ALBERTO MARTINELLI \\ Maurício C. Serafim - Isabela Leao}

econômica que conserve uma economia aberta sem perder o controle dos processos (o que não é fácil de se fazer, mas possível, mesmo em um contexto de enfraquecimento da soberania nacional).

Há uma tensão visível entre as diferentes tendências, tais como interdependência versus fragmentação. Você mencionou em seu livro que se deve dar mais atenção à governança global. Por quê?

A época atual é caracterizada pela contradição entre a interdependência econômico-tecnológica e a fragmentação política, entre a interconexão social e a heterogeneidade cultural. Em outros termos, em âmbito mundial há um déficit de governança; não existe uma forma unívoca e inevitável de globalização, mas a configuração que essa globalização pode assumir e os efeitos positivos e negativos que pode produzir dependem da modalidade de regulação e do governo do processo. A governança global não pode acontecer por meio de um governo mundial ou pelo domínio de uma superpotência, mas deve ser o resultado da interação dialética de instituições e normas que se remete aos princípios do intercâmbio, da autoridade e da solidariedade, produzindo uma forma complexa, multipolar e multinível. A primeira vez que apresentei este argumento foi em meu discurso presidencial no Congresso Mundial de Sociologia em 2002, na Austrália, e mais recentemente em meu livro Global Modernization.

Você acredita que há a necessidade de se modificar a perspectiva dos estudos da ciência política das relações internacionais na direção de uma "global politics"?

Para se compreender a política mundial e contemporânea é necessário pesquisar-se não apenas as estratégias dos Estados nacionais e das organizações governativas internacionais, mas também os comportamentos das organizações internacionais não governativas, dos movimentos sociais e das comunidades religiosas e étnicas transnacionais, das empresas transnacionais e dos mercados internacionais, das comunidades científicas internacionais, e por último, mas não menos importante, das uniões supranacionais, como a União Européia.

E para finalizar, você trabalhou com Neil Smelser nos Estados Unidos. Poderia nos contar um pouco de como foi trabalhar com ele?

Smelser foi o presidente da banca do meu doutorame nto na Universidade da Califórnia, Berkeley, e nos tornamos bons amigos. Tenho apreço em particular pela sua inteligência, sua seriedade profissional, seu empenho no desenvolvimento da pesquisa científica e na formação de jovens pesquisadores, e pela 
sua sólida cultura democrática. Trabalhamos juntos em alguns projetos editoriais, como a nova edição da International Encyclopedia of the Social and Behavioural Sciences (Elsevier, 2004), na qual Smelser foi o editor geral, juntamente com Paul Baltes, e eu fui o section editor de Organization and Management; a coleção Economy and Society (Sage, 1990), que apresentou o estado da arte dos estudos de Sociologia Econômica até então; e o livro The New International Economy (Sage, 1982). Também trabalhamos juntos em atividades do Research Committee on Economy and Society da International Sociological Association (ISA), cuja constituição propusemos, unindo esforços com Fernando Henrique Cardoso, Harry Makler e Arnaud Sales no Congresso da ISA de 1978, em Uppsala (Suécia).

Artigo convidado. Aprovado em 15.10.2007. 